\title{
Analyzing the Role of English 'Loan Lexis' in the Process of Language Change in Contemporary Bodo Linguistic Community
}

By Nobin Narzary

(M.Phil Research Scholar, Bodoland University, Kokrajhar)

Email: nobinnarz@gmail.com

Mobile: $8638867124 / 9615143005$

\subsection{Abstract}

Language grows, evolves and develops over a period of time. Reading through old English writings even the native speakers of today would struggle understanding them. No language (including Bodo) is exempt from this fact. According to Edward Sapir an American Linguist, Language contact is one of the main reasons behind such change in a particular linguistic community. Darwin says that 'languages tended to change in the direction of having shorter easier forms, and that it could be explained by natural selection.'

My close observation lead me to discover that there are numerous English 'loan words that the 'Bodos' use in their conversations. This is a case not only of one linguistic community but of most North East Indian linguistic communities; we can't deny the fact that English Loan words have found great usage in our conversations, TV shows, songs, films and functions. This practice has to a certain extent ushered in some changes in contemporary Bodo linguistic community.

Edward Sapir talks about how one linguistic community borrows vocabulary from another in the process of cultural and social interaction; this he says has been a common phenomenon among linguistic communities in the history and continues to prevail as a common practice till today. In my paper I discuss the causes of such a practice and their possible pros and cons with special reference to Contemporary Bodo linguistic community.

Key words: Loan words, borrowing, language change, cause of borrowing, consequences. 


\subsection{Introduction}

Language grows, evolves, develops and changes over a period of time. Language contact is one of the main reasons behind such change in a linguistic community. In my observation of the 'Bodo' linguistic community I have noticed that there are numerous words of English origin that 'Bodos' as a community use in their verbal interactions. Apart from English words, Bodos have also adopted numerous Assamese, Bengali and Hindi words in many parts of Assam for purposes of communication.

In this research article I intend to carry out an in-depth study of how the 'Bodos' use 'English loan lexis' in their day to day conversations. Most of these words are used unknowingly and often inadvertently. Through this research I attempt to bring some awareness among the 'Bodo' speaking community on the usage and adaptation of English lexis. While trying to delve into a qualitative research in this area I would also attempt at understanding on the possible historical rationale behind such wide usage of foreign lexis.

To analyze and study the phenomenon of English vocabulary usage in Bodo colloquial discourse I have used Edward Sapir's Theory of 'Language Change through Loan Words'. Sapir a Linguist talks about how one linguistic community borrows vocabulary from another for daily usage. This he says has been a common phenomenon among linguistic communities in the history and continues to prevail as a common practice till today.

It might be true to claim that wide usage of English lexis might not have found its place in the literature produced by Bodo scholars and writers of native Bodo language. However, my area of research is the language used by common Bodo folk for conversational purposes which plays a great role in language change. The basic question that I intend to find an answer to in my research is, "How and why has English vocabulary found such wide and prominent usage among the Bodos in their day to day communication?' what are some of the possible reasons behind? What are some of the possible pros and cons of such a practice?

It is an observed fact that many Bodos (literate and illiterate alike) use English words freely while conversing. This phenomenon is observed not merely among the English educated lot, but also among the village dwellers of some far flung villages of Bodo 
dominated districts of Assam. It is to be noted that sometimes these folks use those terms in their literal English sense however at other times they use them to connote things that may not have literal significance to actual English terms (use of words like 'policy,' 'danger,' etc.,). While usage of those terms serve a very practical purpose it could gradually lead to loss of certain native vocabulary.

\subsection{Understanding the Concept of 'Loan Lexis/Borrowing'}

When any part of the structure of a language is changed by importation of features, whether from some other part of the language or from some external source, the imported features are said to be borrowed/loaned. 'External borrowings' could imply those from one dialect to another (dialectical borrowings), those from an earlier stage of the same language (archaisms), and those from other languages (loans). It is very frequent for a language to borrow lexical items from related dialects (regional, social, occupational) for various reasons. Borrowing is a very common linguistic phenomenon; No language is completely free of borrowed forms. Languages change through the influence of other languages. Some languages borrow too largely, others only to a limited extent. (Varshney, 1995).

It is said that of all linguistic elements, 'meaning' is probably the least resistant to change. There is a popular proverb in Indian villages which says that 'language changes every six miles.' One of the results is that all grammars leak because language is not a static entity. In fact a popular definition of language describes it thus, 'language is modifiable, extendable and language changes in time and space.' (Varshney, 1995).

Living languages, indeed, never hold still they continually change their sounds, their grammar, their vocabulary and their meaning for various reasons. A look at Chaucer or Shakespeare's works show how English sounds and spellings have changed. Hindi once had no terms such as radio, television, train, signal etc. Thus, we see the phenomenon of language change everywhere. It is the reality of language; a characteristic trait of every existing language on the planet. Most of these changes in a language are gradual, systematic and minor. They seem so natural that they escape our attention and remain imperceptible. However, over a span of time their effect becomes noticeable. (Varshney, 1995). 


\subsection{Edward Sapir's Theory of Language Change through Borrowing}

According to Edward Sapir (1884-1939), one of the foremost American linguists and anthropologists of his time, "Languages, like cultures, are rarely sufficient unto themselves. The necessities of intercourse bring the speakers of one language into direct or indirect contact with those of neighboring or culturally dominant languages." (Sapir, 1921). The contact between these languages may be friendly or hostile, it may move from ordinary business and trade relations to borrowing of spiritual goods like art, science, religion; it is indeed difficult to find a completely isolated language or dialect. Sapir says, "Language moves down time in a current of its own making. It has a drift... nothing is perfectly static. Every word, every grammatical element, every locution, every sound and accent is a slowly changing configuration, molded by the invisible and impersonal..." (Sapir, 1921)

Often the influence of a language on another is one-directional. The language of a group that is looked upon as a center of culture exerts more influence on other languages used in its vicinity than to be influenced by them. For instance Chinese language has flooded the vocabularies of Korean, Japanese, and others for centuries, but has received nothing in return. In the Western Europe of medieval and modern times French has exercised a similar, though probably a less overwhelming, influence. English borrowed an immense number of words from the French of the Norman invaders. But English has exerted practically no influence on French. (This is exactly what has happened to Bodo language as well in comparison to English language.) The simplest kind of influence that one language may exert on another is the "borrowing" of words. When there is cultural borrowing there is always the likelihood that the associated words may be borrowed too. And so the process has continued uninterruptedly down to the present day, each cultural wave bringing to the language a new deposit of 'loanwords.' (Sapir, 1921)

The careful study of such 'loan-words' indicates a great deal on the history of culture. One can almost estimate the role which various people have played in the development and spread of cultural ideas by taking note of the extent to which their vocabularies have filtered into those of other people. When we realize that an educated Japanese can hardly frame a single literary sentence without the use of Chinese resources we realize how much the 
dominant language has slipped into these languages. It is said that there are just five languages in the world that have had an over-whelming significance as carriers of culture. They are classical Chinese, Sanskrit, Arabic, Greek, and Latin. However, the inter-influence of languages on each other very much depends on how intimate the relations are between one linguistic community to another. (Sapir, 1921)

The study of how a language reacts to the presence of foreign words: rejecting them, translating them, or freely accepting them may throw much valuable light in its innate formal tendencies. The borrowing of foreign words always entails their phonetic modification. There are sure to be foreign sounds or accentual peculiarities that do not fit the native phonetic habits. They are then so changed as to do as little violence as possible to these habits. Frequently we have phonetic compromises. For instance an English word (of French origin) as

the recently introduced "camouflage," as now ordinarily pronounced, corresponds to the typical phonetic usage of neither English nor French. (Sapir, 1921)

\subsection{Causes of Borrowing/Loan}

It is important to understand the conditions under which borrowing of words from one language to another happens. Whenever two idiolects/languages come into contact one or both may be modified. In a face to face communication either speaker may imitate some feature of the other's speech when the contact is indirect (as in reading the influence can of course pass only in one direction). In the case of the 'Bodo' language too, it is a one directional change. The feature which is imitated is called the 'model' and the language in which the 'model' occurs is called the 'donor'. The process itself is called borrowing but this term requires some caution because that which is borrowed does not have to be paid back, the 'donor' makes no sacrifice and does not have to be asked for permission. Indeed, nothing changes the 'donor,' in this entire process in fact the 'donor' goes on speaking as before and only the borrower's speech is altered. (Hockett, 2017).

It is said that conditions for borrowing are present constantly as a natural accompaniment of every use of language. In the contact of two idiolects A and B the chances that borrowing will actually occur depend on several factors, one of which is the degree of similarity of A and B. if the two idiolects are very similar borrowing is unlikely, since neither 
speaker is apt to use any form unknown to the other. On the other hand if both the idiolects are so divergent that the speakers cannot understand each other, borrowing is equally unlikely. Between the two extremes is an area where we find the situations in which borrowing is more probable. (Hockett, 2017). Let us discuss some of the important reasons behind borrowing of Words from one language to another:

\subsubsection{Due to Necessity and Fashion}

The creation of new lexical items is partly because of necessity and partly because of fashion. Necessity arises when a world is lost for linguistic reasons, such as attrition or homonymic clash. In such cases, obviously a new one must take its place. Similarly, if the meaning of a word is devalued another one must be put in the gap left by the devalued one. Also new inventions require new words. But at other times new words arise purely through fashion. New words spring up alongside older words. At first, these new alternatives may be regarded as slang, but in the course of time many of them become increasingly common. The continual infiltration of new lexical items is a normal and healthy trend. It testifies to the essential productivity of language that is the ability to say new things and deal with new situations. (Varshney, 1995).

Borrowing is never a linguistic necessity, since it is always possible to extend and modify the use of existing lexical items to meet new communication needs. A common cause of lexical borrowing is the need to find words for objects, concepts, and places. It is easier to borrow and existing term from another language than to make one up. This is one of the basic reasons why 'Bodos' as linguistic community has borrowed many from English. The paths of lexical borrowing reflect to a certain extent the paths of cultural influence. (Varshney, 1995).

\subsubsection{Mass Effect}

Borrowing is presumed to be the most important mechanism by which a language continues to change. But if such a single act of borrowing were not followed or accompanied by others it could lead to no measurable results in the later history of the language as a whole. Unless number of people living at a particular period of time in history start using those words, the 'loan words' fail to make an impact on the linguistic community. And the words disappear gradually. Thus, in order that the loan lexis survive the test of time they should get 
popularized and generally accepted by a linguistic Community. (Hockett, 2017). Thus, we see that individual borrowing has practically no impact on the linguistic community unless it goes on to have mass effect on a community.

\subsubsection{The Two Possible Conditions under which Borrowing Happens}

The mere contact of idiolects does not guarantee that one will borrow from the other. For borrowing to occur say from B to A, two conditions must be met: firstly, the speaker of A must understand, or think he understands the particular utterance in idiolect B which contains the 'model,' and secondly, the speaker of A must have some motive for borrowing. (Hockett, 2017). Unless these two conditions exist in two contact idiolects/languages borrowing cannot take place.

\subsubsection{The Desire for Prestige}

People imitate those whom they admire this happens in the context of speech as well as other aspects. For instance, upper and middle class Englishmen in the days after the Norman Conquest learned French and used French expressions in their English because French was the language of the new rulers of the country. (Hockett, 2017).

Sometimes the motive is somewhat different, the imitator does not necessarily admire those whom he imitates, but wishes to be identified with them and thus be treated as they are. There is one negative variety of prestige that is of conformity with the majority. This practice happens because of the discomforting experience to be a minority. (Hockett, 2017). The prestige motive is constantly operative in dialect borrowing. When speakers of two different languages live intermingled in a single region, usually one of the languages is that spoken by those in power; this is the upper or dominant language and the other is the lower. The prestige factor leads to extensive borrowing from the dominant language into the lower. (Hockett, 2017).

\subsubsection{The Need-Filling Motive}

The most obvious other motive for borrowing is to fill a gap in the borrowing idiolect. Thus, new experiences, new objects and practices bring new words into a language. Among the new things which migrants or conquerors encounter are natural and artificial topographical 
features and place names which are often passed down from the earlier inhabitants of a region to later arrivals. Immigrants to the United States in the last seventy five years have drawn heavily on English for new words partly on the prestige basis and partly for need filling purposes. In exchange however American English has acquired only a sparse scattering of need filling loans from the various languages of the immigrants. (Hockett, 2017).

It is said, "If a local dialect gains ascendancy for political and economic reasons, then one expects extensive borrowing from that dialect for prestige reasons but forms borrowed into the ascendant dialect have to be understood as the possible case of need-filling." (Hockett, 2017).

\subsection{The Bodo Linguistic Community}

The Bodo language belongs to the western branch of the Barish section under Baric division of the Sino-Tibetan family, as per the classification given by Robert Shafer. The linguistic survey of India describes the Bodos as a member of the Bodo sub-section under the Assam-Burma group of the Tibeto-Burman branch of the Sino-Tibetan or Tibeto-Chinese speech family. The standard form of the Bodo may be taken as that of Darrang which has the advantage of being illustrated in Mr. Engle's excellent little grammar. (K Brahma, 1992).

The Bodo language is said to have no inherited script at present. Shri. Bishnu Prasad Rabha, the famous artist of Assam says that in ancient times there was a kind of 'Deodhai' scripts among the Kacharis (Bodos and Dimasas). However, it has been lost and there are very little traces of it at present. In the recent past the Bodos used Assamese alphabets and Roman alphabets which they had modified to suit their needs. The Bodo Christians mostly used Roman scripts to write their text books and religious matters whereas other would use Assamese. A section of the Bodo Sahitya Sabha had accepted the modified Assamese script for use in their text books and literature while another section of people was in favour of Devanagri script. Thus, there was misunderstanding, disagreements and discussions on the issue. Later Devanagri was accepted the standard script by the Bodos. Since 1963 the Bodo language has been introduced as the medium of instruction in the Bodo predominant primary schools of Kokrajhar sub-division. This has further extended up to secondary stage of education throughout the state of Assam. (K Brahma, 1992). 
The Bodo literature consist of the vast amount of oral literature including folksongs, folktales, ballads and proverbs and of considerable amount of written and published literature in Assamese and Roman scripts. The published literature comprises of books relating to prayers and songs, poems, stories on the one hand and journals and magazines with different types of prose and verse on the other hand. There are unpublished novels and dramas too. (K Brahma, 1992).

The lack of an authentic written history of the Bodo Language can be supposed to be the main fault of the Bodo people of the old; who were concerned only with ruling and least bothered about preserving the language in written form. This is evident by the fact that most of the historical legendary figures of the greater Bodo community were eminent rulers like Raja Iragdao (last king of the Bodos whose kingdom was invaded by the East India Company in 1824 through the Doctrine of Lapse. He is also known as Gobindra Chandra in history), Sikhwna Jwhwlao, Swmdwn Jwhwlao, Gambari Sikhla, Birgwsri Sikhla etc. another possible reason maybe the lack of habit of preserving old books and records. The Bodos have a habit of destroying all the belongings of a person at the time of his/her funeral ceremony. (A Brahma, 2007).

\subsection{Impact of English Loan Lexis in Contemporary Bodo Linguistic Community}

In the previous section we have discussed various reasons behind the practice of borrowing words from one linguistic community to another. Most of those causes apply to 'Bodo' Linguistic community as well. For instance certain words are borrowed due to Necessity as there are no words to actually represent those concepts or objects; for instance electronic gadgets, newly discovered objects etc. need new names. There are times when words are borrowed for the sake of fashion as well. One of the reasons why many English words have sipped in Bodo linguistic community is also due to mass acceptance of those words. The community has been able to understand English lexis to a certain extent because of which there has arisen willingness to use those words. Desire for prestige too has been one of the reasons for the borrowing of such words. Another important reason has been need filling motive; the Bodo linguistic community in order to fill the gaps of lack of terms for certain concepts and objects have adopted English lexis. 
Some of the major reasons for such practices are: Colonization (India was under British rule for over 200 years which had a great influence in Indian languages. Bodos too came in close contact with the British which would have influenced in some way; there were many Bodo rulers who fought against the British, which suggests that Bodos ruled their kingdom and had great influence at the time of British rule). Another important reason for borrowing English lexis among Bodos could be the Influence of Mass media and communication (Today, T.V shows, Movies, Video games etc. influence the society in a great way today). Missionary Education or English Medium Schools and Colleges too have contributed to the phenomenon of language change due to borrowing of English lexis.

A look at the Bodo Linguistic community shows how the Bodo Community came in contact with many linguistic communities over the years. This contact has influenced the community linguistically. Apart from the English influence which happened in recent years. The community has been influenced by various languages such as Assamese, Hindi, Bengali etc.

Most Bodos of today use English lexis to describe even ordinary household tools like "Table," "Chair," "Bench," etc., in literal sense of the English terms and most of them do not know the actual 'Bodo' words for the same.' It has been a huge surprise for me to discover that Bodos use the term 'Sun' to describe Sun. It appears to be the case of borrowing from the English word 'Sun'. Bodos do not have another term to describe it. Thus, the etymological search this term remains intriguing.

In my analysis of the interview (in Bodo language) of Mr. Biswajit Daimary the present the Rajya Sabha M.P from Kokrajhar (ST) Constituency used over four hundred English words in his 30 minutes interaction with a local Bodo journalist (of Bodoland Radab Channel) on $22^{\text {nd }}$ February 2021.

The present Chief Executive Member of the Bodoland Territorial Council Mr. Promod Boro used over 300 English loan words in his 28 minutes interview with the Bodoland Radab Channel on $6^{\text {th }}$ October 2020. 
Mr. Hagrama Mohilary the former Chief Executive Member of Bodoland Territorial Council used over 300 words in his 37 minutes interview on $26^{\text {th }}$ February 2020 with Engkhong Television Channel.

Mr. Ranjit Basumatary the present Executive Member of Bodoland Territorial Council used about 50 English words in his 9 minutes interaction with a popular Bodo YouTube channel (Bodoland Mission Swdwb Channel) on 24 ${ }^{\text {th }}$ April 2020.

A Bodo journalist of Bodoland Engkhong Television channel used over 90 words in 10 minutes of Bodo news reading on $4^{\text {th }}$ March 2021.

Mr. Gobinda Basumatary the present Deputy Chief Executive Member of Bodoland Territorial Council used about 120 words in his 24 minutes interview with Prakash Narzary (in Bodoland Mission Swdwb Channel) on $1^{\text {st }}$ February 2020.

Analyzing the above mentioned interviews and discussions in native Bodo language exposes the fact that Bodos as linguistic community has become very dependent on 'English loan lexis' for their day to day conversations and communication. Such a practice does have its pros and cons. However, the fact is that such a practice within a linguistic community is unavoidable. On the one hand it makes a linguistic community more global and understandable to the second language learners. On the other hand it does make a linguistic community lexically poor over the years.

\subsection{Conclusion}

The fact that languages changes can neither be disputed nor denied. There have been several attempts to psychologically prevent and discourage this practice however it has never actually been successful. The movements by Non-governmental organizations, student unions, and various other organizations have failed because this is a universal fact in every language. It is the desire of every linguistic community to preserve one's native language in its pristine form but the fact is language changes gradually. Language is dynamic in nature. No language in the world has ever been able to resist influence by another. Language change has been a common experience for every linguistic community and will continue to be so in the future too. 
My attempt has been to bring awareness of the fact that in the recent time there has been gradual but significant usage of English loan words among contemporary Bodo linguistic community for certain reasons. The loan words that a linguistic community adopts at a point in time could certainly lead to some change in language in the long run especially when such words gain wide usage over a prolonged period of time by big number of the speakers of that language. Most linguists like Edward Sapir, Leonard Bloomfield and others realized the importance of 'borrowing' as a mechanism for language change and in fact it is one of the most important tool that aides language change.

\section{REFERENCES}

1. Brahma, Allendra. An Introduction to Bodo Phonology. Guwahati, Bhabani Books, 2015.

2. Brahma, Kameshwar. A Study of Socio-Religious Beliefs, Practices and Ceremonies of the Bodos. Calcutta, Punthi Pustak, 1992.

3. Endle, Sidney. The Kacharis. Wilmington, Franklin Classics, 2018.

4. Hockett F. Charles. A Course in Modern Linguistics. Delhi, Surjeet Publications, 2017.

5. Lyons, John. Language and Linguistics: An Introduction. Cambridge, Cambridge University Press, 1981.

6. Sapir, Edward. Language: An Introduction to the Study of Speech. New York, Harcourt Brace, 1921.

7. Varshney L. Radhey. An Introductory Textbook of Linguistics and Phonetics. Bareilly, Student Store, 2015.

8. "Boro Language (India)." Wikipedia, en.wikipedia.org/wiki/Boro_language_(India). Accessed 08 Mar. 2021.

9. The Editors of Encyclopaedia Britannica. "Bodo | People." Encyclopedia Britannica, www.britannica.com/topic/Bodo-people. Accessed 08 Mar. 2021. 
10. Interviews:

11. "MP बिस्वजित दैमारीजों BODOLAND रादाब आव गोनांथार आयदाखौ लानानै मोगा-मोगि सावरायलायनाय।." YouTube, uploaded by BODOLAND रादाब, 22 Feb. 2021, www.youtube.com/watch?v=ExjEzWA0RRE\&t=356s.

12. "सनितपुर आरो बिस्वनात जिल्लानि माखासे जेंनाफोरखौ लानानै प्रमद बर'जों मोगा-मोगि." YouTube, uploaded by BODOLAND रादाब, 6 Oct. 2020, www.youtube.com/watch?v=1YxbL-dTBx0.

13. "Exclusive Interview with Hagrama Mohilary, Chief, Bodoland (Bodoland Engkhong Television) 26-02-2020." YouTube, uploaded by Bodoland Engkhong Television, 26 Feb. 2020, www.youtube.com/watch?v=kjANGDmY5P4.

14. "UPPL हाबनाय जाहोननि सोमोन्दै,Mr Ranjit Basumatary ( Ferenga ),14 No Chirang Duar Constituency( UPPL)." YouTube, uploaded by Bodoland Mission सोदोब, 24 Apr. 2020, www.youtube.com/watch?v=bjrwrhlfUMM.

15. "04/03/2021Bodo News." YouTube, uploaded by BODOLAND ENGKHONG TELEVISION, 4 Mar. 2021, www.youtube.com/watch?v=4HpBelVhDpQ.

16. "आफाद गोदान दानाय - Mr.Govinda, NDFB(P) मोगा-मोगि ( Interview ), Banasur Highway,BTR - Prakash Narzary.” YouTube, uploaded by Bodoland Mission सोदोब, 1 Feb. 2020, www.youtube.com/watch?v=TCI36vjN5eo. 